\title{
Tourism climatology: past, present, and future
}

\author{
Michelle Rutty ${ }^{1} \cdot$ Robert Steiger $^{2}$ (D) $\cdot$ O. Cenk Demiroglu ${ }^{3}$ (I) $\cdot$ David R. Perkins $^{4}$ (I)
}

Published online: 8 January 2021

(C) ISB 2021

\section{Commission on Climate, Tourism and Recreation}

Founded in 1999 at the $15^{\text {th }}$ International Congress of Biometeorology, the Commission on Climate, Tourism and Recreation (CCTR) is an international working group that seeks to advance the current state of knowledge in the field of tourism/recreation climatology. Beginning in the 1970s, climatologists explored how climate impacts a myriad of economic sectors, including tourism, with research predominantly centered on how climatological information could be used within the context of tourism planning processes (Lamb 2002). After a brief decline in research activity in the $1980 \mathrm{~s}$, a new phase of research growth, propelled by climate change, emerged in the 1990s (Scott \& Lemieux 2010). As noted by de Freitas (2017), the field is now truly multidisciplinary, with a range of disciplines contributing diverse methodologies to understand the climate and tourism nexus. Over the past five

Announcement: The sixth CCTR event, with support from the Arctic Research Centre at Umeå University (ARCUM), will take place virtually in the spring of 2021. For further information, please go to www. cctr2021.org.

Michelle Rutty

mkrutty@uwaterloo.ca

Robert Steiger

robert.steiger@uibk.ac.at

O. Cenk Demiroglu

cenk.demiroglu@umu.se

David R. Perkins

davidperkins@missouristate.edu

1 Faculty of Environment, University of Waterloo, Waterloo, Canada

2 Department of Public Finance, University of Innsbruck, Innsbruck, Austria

3 Department of Geography, Umeå University, Umeå, Sweden

4 Department of Geography, Geology, and Planning, Missouri State University, Springfield, USA decades, the two-way relationship between climate and tourism that was once assumed is now empirically observed, objectively tested, and incorporates concepts and theoretical frameworks that support continued model development and global comparisons. The CCTR has facilitated and engaged the growing number of researchers in the field, building collaborative partnerships with industry leaders, identifying key knowledge gaps, and setting research priorities to continually advance the state of knowledge.

To date, there have been five international meetings of the CCTR. The fifth conference took place in Umeå (Sweden) in 2018, bringing together scholars and tourism experts from 16 different countries to discuss recent developments in tourism climatology. The workshop focused on improving climate services for the tourism sector, as well as enhanced our understanding of sectoral climate change risks and opportunities. The meeting launched with a keynote by Dr. Daniel Scott, widely considered a leader in the field (Fang et al. 2018; Becken 2013), followed by a panel discussion with the CCTR co-chairs (authors) that reflected on research priorities and progress made since the inaugural workshop in 2003 (see Matzarakis et al. 2004). This paper offers a summary of the advancements made over the last two decades since the inception of the CCTR, including a research agenda for continued progress. Next, an overview of the ten research papers included in this special issue is provided, which was open to all workshop participants.

\section{Tourism climatology: past and present}

The first journal articles published using the term "tourism/recreation climatology" appeared in the 1970s (e.g., Danilova 1974; Crowe et al. 1977; Singh 1977; Besancenot et al. 1978), with the first articles linking climate change and tourism published in the 1980s (e.g., Wall et al. 1986; McBoyle \& Wall 1987; Wall et al. 1988), and the CCTR founded shortly thereafter in the 1990s. In a bibliometric analysis of Web of Science (1978-2017), there are over 2000 records using the terms "tourism" or "recreation" and either "weather" or "climate" in the 
titles or abstracts, with just $15 \%$ (or 299 records) published during the CCTR's first three workshops (2002-2008) (Scott 2018). Importantly, almost half of the publication records at this time came from CCTR proceedings, laying the foundation for international teams to contribute to two high-profile reports that set the research agenda for the following decade.

First, commissioned by the United Nations World Tourism Organization (UNWTO), the United Nations Environment Program (UNEP), and the World Meteorological Organization (WMO), Climate Change and Tourism Responding to Global Challenges, was led by the then CCTR co-chair Dr. Daniel Scott (UNWTO et al. 2008). The report underscored that climate change must be considered "the greatest challenge to sustainable tourism in the $21^{\text {st }}$ century" (UNWTO et al. 2008, p. 38), shifting the focus of tourism climatology research toward climate change (impacts, adaptation, mitigation). Second, a White Paper for the tourism sector was presented at the $3^{\text {rd }}$ World Climate Conference in Geneva Switzerland, which led by a CCTR co-chair, indicating that international bodies recognized the need for improving knowledge in this area (de Freitas 2017; Scott et al. 2011). The paper outlined the multifaceted and complex interface between climate and tourism, including the sector's high climate sensitivity and the range of climate services sought by diverse sectoral stakeholders (e.g., tourists, operators, planners, investors, insurers, government agencies, tourism organizations) (Scott and Lemieux 2010). As the spotlight on tourism climatology took a global stage, publications soared from approximately 20-50 publications per year (2000-2008), to nearly 300 per year by the CCTR's fourth conference in 2015 (Scott 2018). The explosion of research subsequently strengthened tourism's position in the Intergovernmental Panel on Climate Change (IPCC) Fifth Assessment Report (AR5) (e.g., 450 tourism citations in AR5) (Scott et al. 2016a), further boosting the global recognition of the integrated and transboundary impacts of tourism and climate, including the sector's contribution to greenhouse gas emissions and the urgent need for tourism to participate in mitigation efforts.

As evidenced by this special issue, the research stemming from the CCTR is now more diverse than ever, with researchers from a broad range of disciplines and across an increasing number of countries contributing to the growing literature in this field. It is clear that there is growing interest among emerging scholars (e.g., graduate students, early-career scientists), as well as across disciplinary boundaries and public-private collaborations. The ten research papers included in this issue on Climate, Tourism and Recreation are indicative of the broad range of tourism activities (skiing, coastal, park, sightseeing), geographical contexts (North America, Western and Eastern Europe, China, polar regions), and disciplines (business, economics, geography, environmental science, marketing, meteorology, tourism) that are engaged in the rapidly advancing field of tourism climatology.

\section{Special issue papers}

Among the most-studied research areas in the tourism climatology literature is snow sports tourism, which is understandable given its reliance on climatic resources (i.e., low temperatures, snowfall) and thereby high vulnerability to climate change (Steiger et al. 2019). Five contributions to this special issue examine ski tourism, but in unique methodological ways. Using a time-varying model to provide new evidence on the changing relationship between overnight stays and natural snow conditions at winter resorts in Sweden, Norway, and Austria, Falk and Lin (2019) reveal tourists' sensitivity to natural snow conditions varies markedly depending on location and time period of the stay. Over the last 17 years, Berard-Chenu et al. (2020) found that regardless of elevation or resort size, snowmaking has been the second investment item for over 100 ski resorts in the French Alps (e.g., ski lift operators dedicated approximately $20 \%$ of their investments for snowmaking). These findings align with Fang et al. (2019), who project that snowmaking needs in China will increase by an average of $27-80 \%$ by mid-century (2050s RCP 4.5 and 8.5, respectively), requiring substantial future investments in snowmaking infrastructure. Applying a ski season simulation model, the study underscores the highly regional climate change risk to ski resorts in China, which until now has been an important geographical gap in the tourism climatology literature. With the increase in studies that examine climate impacts on ski tourism, Abegg et al. (2020) critically review the importance of technical and operational snow indicators, providing quantitative measures and specifications that can be applied to large temporal and spatial scale ski assessments of climate change effects on ski tourism. Key indicators include white winter landscape, snow days, start/ end of the snow season, and snowmaking potential.

Following the snow and ice, Welling and Abegg (2019) conducted interviews with glacier tour operators in Southeast Iceland and found that all entrepreneurs considered climate change to be a concern for daily operations, but that these implications are not significant threats to their business. Unlike ski resorts, glacier operators have adopted a wait-andsee strategy, postponing proactive long-term operational adaptation strategies. The development of new tourist routes in polar regions (Arctic, Antarctic, Tibetan Plateau) is also of increasing interest, with potential climate risks for those tourists opting to travel to extreme cold and high-altitude environments. Grigorieva (2020) developed the Acclimatization Thermal Strain Index for Tourism (ATSIT) to quantify the physiological strain travelers experience during the acclimatization process and, in turn, aid with intervention procedures to minimize negative health implications. Walking is another key tourism activity, yet there is little research on walkability from a tourist perspective, including the extent to which weather and climatic conditions influence tourist walking 
behavior. In a critical literature review conducted by Hall and Ram (2019), strategies for future walkability research are provided, such as the need to address issues such as comfort, connectivity, safety, and aesthetic values.

Another area of tourism climatology research that has evolved greatly over the past several decades has been the development of indices. The first composite Tourism Climate Index (TCI) developed by Mieczkowski (1985) has since been widely applied across tourism environments despite notable criticisms (Scott et al. 2016b; Rutty et al. 2020). The contributions in this special issue address such concerns and make valuable contributions moving forward. For example, in the first application of the Holiday Climate Index (HCI):Beach in the Asia-Pacific tourism region, the results from $\mathrm{Yu}$ et al. (2020) underscore the inappropriate use of the TCI when assessing $3 \mathrm{~S}$ (sun, sea, sand) tourism potential, with key rating differences found when assessing the climatic suitability of beach destinations across China. Matthews et al. (2019) combined the use of expert knowledge, stated visitor preferences, and mathematical optimization to develop an index that captures the unique contextual realities of Great Lakes beach park tourism, which outperformed both the TCI and HCI:Beach. Demiroglu et al. (2020) developed the first Ski Climate Index (SCI), applying snow reliability, thermal comfort, and aesthetic facets specifically tailored for snow tourism to evaluate which regions in Turkey are most suitable for future ski resort development.

\section{Moving forward}

From inception, the CCTR has sought to bring together scientists and tourism experts to review the current state of knowledge of tourism climatology, while exploring future areas of inquiry by supporting multi- and interdisciplinary collaborations. Throughout the past two decades, the CCTR mission has remained largely unchanged, with each workshop highlighting the continued growth and development of tourism climatology. Reflecting on the CCTR's past and present, the 5th workshop also focused on strategic needs and opportunities for the field of tourism climatology moving forward. First, there continues to be major regional gaps in climatology research, with studies highly concentrated in temperate, developed countries (i.e., Europe, North America, Australia, New Zealand). While we have made progress (see Demiroglu et al. 2020; Grigorieva 2020; Yu et al. 2020 in this issue), major geographical gaps persist in Africa, Asia, and South America, with an urgent need to build collaborative partnerships and prioritize interdisciplinary research within these regions.

In addition to expanding our regional expertise, there is also a continued need to engage with industry partners to yield decision-relevant knowledge, including knowledge mobilization through improved climate services in tourism (i.e., scientifically based information and products that enhance users' knowledge and understanding about the impacts of climate and their decisions and actions). Although public-private partnerships within CCTR are increasing (e.g., Rutty et al. 2020 in this issue), researchers often use assumptions or anecdotal evidence to determine what climatic information is required by the tourism sector. There remains a limited number of collaborative studies between researchers and industry stakeholders, which can create barriers to progress and hinder knowledge advancements. How do industry stakeholders, including tourists, prepare for, observe, predict, and respond to weather and climate (particularly hazards or extremes, which are becoming more common)? Where and when do stakeholders gather their climate-related information, and what is the best way to present this information to the broad range of end-users? Although significant work has been done in the meteorology community in terms of understanding the general public's climate service needs, it is unclear (and unlikely) that we can generalize such findings in a tourism context. Effective climate services for tourism will require collaboration between providers and users to better assess information needs and to enhance climatic resiliency within tourism, as well as help the sector adapt to a warming and decarbonizing future.

Continued research that addresses the role of extreme and catastrophic weather events on the tourism system is also needed. There remains a limited understanding of how extreme climate events (e.g., droughts, floods, hurricanes, heatwaves) impact tourists' decision-making, including travel planning, arrivals, spending, and overall trip satisfaction. Climate change is anticipated to alter the frequency, intensity, spatial extent, duration, and timing of extremes, resulting in unprecedented catastrophic events (Hoegh-Guldberg et al. 2018). Temporal analogues continue to be a promising, yet underutilized, method in tourism studies, which can reveal important information about the adaptive responses of tourism stakeholders to make inferences about the future (Rutty et al. 2017). With record-breaking events (e.g., July 2019 European heat wave) and hurricanes (e.g., historic 2017 season in the Caribbean), there are opportunities available for researchers to explore how stakeholders have managed and responded to extreme climatic conditions. Similarly, there are opportunities to explore the impact of climate-driven environmental changes, including coral bleaching and wildfire events. Since climate alone does not determine or explain the response or behavior of tourist and the tourism industry, an exploration of past events can shed light on the social sensitivity of people to climatic stimuli to better understand the contextual factors that can attenuate responses.

\section{Conclusion}

The growing diversity of disciplines contributing to this field of tourism climatology research mirrors the complexity of the 
field. While in the emergent phase of tourism climatology, a majority of studies were either strong in climatology or tourism leading to a rather one-dimensional representation of this complex system and its interrelationships. The development of the literature over the last decade and the contributions in this special issue reflect a growing awareness of this complexity, providing important opportunities for interdisciplinary research that opens up paths for methodological advancements and innovation.

Today, more than ever, as the world faces the ever-present challenges and threats of a warming climate, the need to advance the state of knowledge in the field of tourism/recreation climatology is clear. In addition to reflecting on the past and present, this paper has discussed three key research areas that require the attention of tourism climatologists moving forward. Building on these insights, the sixth CCTR workshop in 2021 will consequently focus on bringing scholars and practitioners from around the globe to share their ongoing research, including an emphasis on climate services, climate change, and extreme weather events. As evidenced by this special issue, the growing international collaborations, including the number of countries, industry leaders, academic disciplines, and emerging scholars that are represented by the CCTR, underscore the promise for developing a critical mass of knowledge that will continue to deliver decision-relevant research for the tourism community and beyond.

Acknowledgments The co-chairs of the ISB-CCTR gratefully acknowledge the members of its Scientific Advisory Board, all of whom contributed to the success of the conference, as well as its keynote and panel moderators: Professor Michael Hall (University of Canterbury, New Zealand), Dr. Linda Lundmark (Umeå University, Sweden), Professor Jarkko Saarinen (University of Oulu, Finland), and Professor Daniel Scott (University of Waterloo, Canada). We would also like to thank Umeå University for hosting, including support from the Arctic Research Centre at Umeå University (ARCUM), The Gösta Skoglund Foundation, Region Västerbotten, and Swedish Research Council for Sustainable Development (FORMAS). We dedicate this special issue in memoriam to Dr. Christopher Rhodes de Freitas (1948-2017), cofounder of CCTR and to whom much advancement in the field of tourism climatology is owed.

\section{References}

Abegg B, Morin S, Demiroglu OC, François H, Rothleitner M, Strasser U (2020) Overloaded! Critical revision and a new conceptual approach for snow indicators in ski tourism. Int J Biometeorol. https://doi.org/ $10.1007 / \mathrm{s} 00484-020-01867-3$

Becken S (2013) A review of tourism and climate change as an evolving knowledge domain. Tour Manag Perspect 6:53-62

Berard-Chenu L, Cognard J, François H, Morin S, George E (2020) Do changes in snow conditions have an impact on snowmaking investments in French Alps ski resorts? Int J Biometeorol. https://doi.org/ 10.1007/s00484-020-01933-w

Besancenot JP, Mounier J, Lavenne FD (1978) Climatological conditions for coastal tourism: a comprehensive research method. Norois 99 : $357-382$
Crowe RB, Baker WM, McKay GA (1977) The tourist and outdoor recreation climate of Ontario (Vol. 2). Atmospheric Environment Service.

Danilova NA (1974) A recreational evaluation of the climate of the Black Sea Coast. Meteorological Translations, no 25. Atmospheric Environment Service, Canada, Department of the Environment, Toronto, pp 17-31

De Freitas CR (2017) Tourism climatology past and present: A review of the role of the ISB commission on climate, tourism and recreation. Int J Biometeorol 61(1):107-114

Demiroglu OC, Turp MT, Kurnaz ML, Abegg B (2020) The Ski Climate Index (SCI): fuzzification and a regional climate modeling application for Turkey. Int J Biometeorol. https://doi.org/10.1007/s00484020-01991-0

Falk M, Lin X (2019) Time-varying impact of snow depth on tourism in selected regions. Int J Biometeorol. https://doi.org/10.1007/s00484019-01848-1

Fang Y, Yin J, Wu B (2018) Climate change and tourism: a scientometric analysis using CiteSpace. J Sustain Tour 26(1):108-126

Fang Y, Scott D, Steiger R (2019) The impact of climate change on ski resorts in China. Int J Biometeorol. https://doi.org/10.1007/s00484$019-01822-\mathrm{x}$

Grigorieva EA (2020) Adventurous tourism: acclimatization problems and decisions in trans-boundary travels. Int J Biometeorol. https:// doi.org/10.1007/s00484-020-01875-3

Hall CM, Ram Y (2019) Weather and climate in the assessment of tourism-related walkability. Int J Biometeorol. https://doi.org/10. 1007/s00484-0191-01801-2

Hoegh-Guldberg O, Jacob D, Taylor M, Bindi M, Brown S, Camilloni I, Diedhiou A, Djalante R, Ebi KL, Engelbrecht F, Guiot J, Hijioka Y, Mehrotra S, Payne A, Seneviratne SI, Thomas A, Warren R, Zhou G (2018) Impacts of $1.5^{\circ} \mathrm{C}$ global warming on natural and human systems. In: Global warming of $1.5^{\circ} \mathrm{C}$. An IPCC special report. In: Masson-Delmotte V, Zhai P, Pörtner H-O, Roberts D, Skea J, Shukla PR, Pirani A, Moufouma-Okia W, Péan C, Pidcock R, Connors S, Matthews JBR, Chen Y, Zhou X, Gomis MI, Lonnoy E, Maycock T, Tignor M, Waterfield T (eds) Intergovernmental Panel on Climate Change (IPCC). Cambridge University Press, Cambridge, pp 175-311

Lamb HH (2002) Climate, history and the modern world. Routledge, New York

Matthews L, Scott D, Andrey J (2019) Development of a data-driven weather index for beach parks tourism. Int J Biometeorol. https:// doi.org/10.1007/s00484-019-01799-7

Matzarakis A, De Freitas CR, Scott D (2004) Advances in tourism climatology. Universität Freiburg, Freiburg, pp 6-259

McBoyle G, Wall G (1987) The impact of CO2-induced warming on downhill skiing in the Laurentians. Cah Géog Québec 31(82):39-50

Mieczkowski Z (1985) The Tourism Climate Index: a method for evaluating world climate for tourism. Can Geogr 29:220-233

Rutty M, Scott D, Johnson P, Pons M, Steiger R, Vilella M (2017) Using ski industry response to climatic variability to assess climate change risk: an analogue study in Eastern Canada. Tour Manag 58:196-204

Rutty M, Scott D, Matthews L, Burrowes R, Trotman A, Mahon R, Charles A (2020) An inter-comparison of the Holiday Climate Index (HCI: Beach) and the Tourism Climate Index (TCI) to explain Canadian tourism arrivals to the Caribbean. Atmosphere 11(4):412

Scott D (2018) Tourism climatology: past, present, future. Keynote presentation, 5th International Conference on Climate, Tourism and Recreation at Umeå University, Sweden

Scott D, Hall CM, Gössling S (2016a) A review of the IPCC Fifth Assessment and implications for tourism sector climate resilience and decarbonization. J Sustain Tour 24(1):8-30

Scott D, Lemieux C (2010) Weather and climate information for tourism. Procedia Environ Sci 1:146-183 
Scott D, Lemieux C, Malone L (2011) Climate services to support sustainable tourism development and adaptation to climate change. Clim Res 47(1-2):111-122

Scott D, Rutty M, Amelung B, Tang M (2016b) An inter-comparison of the holiday climate index (HCI) and the tourism climate index (TCI) in Europe. Atmosphere 7(6):80

Singh TV (1977) Climatology of recreation: an appraisal of climate as resource-input in Indian tourism. Tour Recreat Res 2(1):1-12

Steiger R, Scott D, Abegg B, Pons M, Aall C (2019) A critical review of climate change risk for ski tourism. Curr Issue Tour 22(11):13431379

UNWTO, UNEP, \& WMO. (2008) Climate change and tourism: responding to global challenges. Madrid: UNWTO, Paris: UNEP, Geneva: WMO
Wall G, Harrison R, Kinnaird V, McBoyle G, Quinlan C (1986) The implications of climatic change for camping in Ontario. Recreat Res Rev 13(1):50-60

Wall G, Harrison R, Kinnaird V, McBoyle G, Quinland C (1988) Implications of climatic change for tourism and recreation in Ontario (No. WU-88-05). University of Waterloo, Waterloo

Welling J, Abegg B (2019) Following the ice: adaptation processes of glacier tour operators in Southeast Iceland. Int J Biometeorol. https://doi.org/10.1007/s00484-019-01779-x

Yu DD, Rutty M, Scott D, Li S (2020) A comparison of the holiday climate index: beach and the tourism climate index across coastal destinations in China. Int J Biometeorol. https://doi.org/10.1007/ s00484-020-01979-w 